\title{
Outcomes of colorectal cancer surgery in the nonagenarians: 20-year result from a tertiary center
}

\author{
Toi Yin Chan ${ }^{1}$, Chi Chung Foo ${ }^{2 *}$, Wai Lun Law² and Oswens Lo ${ }^{1}$
}

\begin{abstract}
Background: There is a foreseeable trend that life expectancy is on the rise in many parts of the world. More and more patients will present with colorectal cancer at extreme old age and advanced age is a well-known risk factor for adverse outcomes after surgery. The aim of this study is to evaluate the outcomes of colorectal cancer surgery in patients aged 90 or above.
\end{abstract}

Method: A retrospective analysis of consecutive patients aged 90 or above who underwent operations for colorectal cancer between January 1996 and December 2015 was performed. The primary outcomes were the complications rate, 30-day and 180-day mortality rates.

Results: A total of 57 patients were included in the analysis. The majority of them were women (64.9\%). The median age was 92 years. Most of the surgery was of curative intent (77.2\%), performed under elective setting (57.9\%) and with open approach (78.9\%). 36.8\% of patients had postoperative complications, with pneumonia being the commonest. The 30-day and 180-day mortality rate was 7 and $31.6 \%$ respectively. History of ischemic heart disease and surgery under emergency setting were predictors of postoperative complications. Pneumonia, preoperative leukocytosis and Charlson comorbidity score $\geq 9$ were predictors of 180-day mortality. The one and two-year survival rate for elective surgery was 69.7 and $54.5 \%$ respectively.

Conclusion: The outcomes of colorectal cancer surgery for nonagenarians could be favorable in a selected group of patients. Future study on better risk profiling and ways to improve outcomes is warranted.

Keywords: Nonagenarian, Colorectal cancer, Elderly

\section{Background}

Life expectancy is rising worldwide, and according to statistics from the United Nations in 2015, 0.8\% of the populations in developed countries were aged 90 or above [1]. This number is expected to triple by 2065, increasing to $3.3 \%$. Citizens of Hong Kong are known to enjoy some of the longest life-expectancies in the world, reaching 81.32 and 87.34 years for men and women respectively [2]. According to the latest projection from the Hong Kong Census and Statistics Department, by year 2066, 428,700 citizens in Hong Kong will be of 90 years old or above, constituting

\footnotetext{
* Correspondence: ccfoo@hku.hk

The corresponding author is not a recipient of a research scholarship.

${ }^{2}$ Department of Surgery, The University of Hong Kong, 102 Pokfulam Road,

Hong Kong, China
}

Full list of author information is available at the end of the article
$5.6 \%$ of the entire population [3]. With improving socio-economic environments and the availability of high quality health care, a similar trend was also observed in other developed regions, such as Australia and some parts of Europe [4]. As a result of this increase in life expectancy, it is increasingly common for physicians to treat patients at the extremes of age. Elderly patients are more likely to have lower physiological reserve and higher American Society of Anesthesiologists (ASA) scores [5].

Colorectal cancer is the leading malignancy in many countries and is especially common in elderly individuals [6]. The decision whether to operate on this group of patients is often difficult due to the higher risk of complications and mortality [7]. To date, there are limited data on the outcome of colorectal cancer surgery in the extreme elderly. 
This study aimed to evaluate the outcomes of colorectal cancer surgery for nonagenarian patients, i.e. patients who were between 90 and 99 years old at the time of surgery, in a tertiary referral center over a 20 -year period.

\section{Methods}

This was a retrospective observational study approved by the Institutional Review Board of the University of Hong Kong/Hospital Authority (UW 18-229). Between January 1996 and December 2015, all patients who suffered from histologically proven adenocarcinoma of the colon and rectum and underwent surgery were entered into a prospectively maintained database. Patients who were lost to follow-up or had incomplete data were excluded. Patients who were aged 90 or above at the time of surgery were reviewed. All patients received broad spectrum antibiotics on induction, covering common colonic microbes such as gram negative bacilli and anaerobes. Bowel preparation was administered to patients undergoing elective surgery unless the tumor was partially obstructing and as a result patients were unable to tolerate the iso-osmotic bowel cleansing agent. The following baseline demographics were retrieved: ASA score, Eastern Cooperative Oncology Group (ECOG) performance status [8], Charlson comorbidity index (CCI) [9], preoperative biochemical markers (serum creatinine, white cell count, albumin, hemoglobin levels), acuity and approach of surgery, tumor characteristics, treatment types, morbidities, 30-day mortality, 180-day mortality, and survival rates. The primary endpoints included postoperative complications, and 30-day and 180-day mortality rates. The secondary endpoints were the factors that could predict complications and mortality.

Univariate analysis was performed on various clinical parameters. Categorical variables were analyzed using the Fisher exact test and the $x^{2}$ test where appropriate. Continuous variables were analyzed using the independent sample t-test. All comparisons were two-sided, and a $p$ value of $<0.05$ was considered statistically significant. Multivariate analysis was performed to identify the predictors for overall complications, and 30-day and 180-day mortality, using a forward stepwise model. Variables with significant univariate association, defined by a $p$ value of $<$ 0.1 , were included in the multivariate analysis. The survival rates of the elective and emergency surgery groups were estimated with the Kaplan-Meier curve. Statistical analysis was performed by SPSS version 20 (IBM Corporation, Armonk, NY, USA).

\section{Results}

During the study period, there were a total of 68 patients who were aged 90 or above at the time of surgery. After excluding those with incomplete data, 57 patients were included in the analysis; the majority of them (64.9\%) were female. The age of patients ranged from 90 to 101 years, with a median age of 92 years; $42.1,52.6$, and $5.3 \%$ of the patients were ASA 2, 3, and 4, respectively (Table 1), and $36.8,49.1$, and $14.0 \%$ of the patients were ECOG 2, 3, and 4, respectively. The CCI ranged from 6 to 13, with a median of $8 ; 73.7 \%$ of patients were non-smokers, and $56.1 \%$ had hypertension, while $10.5 \%$ had a history of ischemic heart disease. The majority of the operations (77.2\%) were of curative intent; $57.9 \%$ were performed under the elective setting and $21.1 \%$ with the laparoscopic approach. The most commonly performed operation was right hemicolectomy (29.8\%). The length of hospital stay ranged from 3 to 57 days, with a median of 9 days. The median followup period was 15.9 months (range, 0.3-115.8 months). None of the patients were lost to follow-up before death.

A total of 21 patients (36.8\%) developed postoperative complications, the majority of which was pneumonia (14.0\%). Four patients developed respiratory failure requiring tracheostomy after surgery. Four patients (7.0\%) developed paralytic ileus, and all resolved with conservative treatment. Five patients $(8.8 \%)$ suffered from myocardial infarction or arrhythmia. Two patients (3.5\%) suffered from urinary tract infections and were managed with antibiotics. One $(1.8 \%)$ suffered from stroke and was treated with aspirin. Two patients (3.5\%) underwent re-operations within the same admission. One of them had anastomotic leakage and intra-abdominal collection after an elective palliative bypass for a cecal tumor. The other developed recurrent inguinal hernia with strangulation after an emergency right hemicolectomy and synchronous bilateral inguinal herniorrhaphy for cancer of the transverse colon; $86 \%$ of the patients were discharged home after various period of rehabilitation. The overall complication rates were 24.2 and $50.0 \%$ for elective and emergency operations, respectively.

Four patients died within the first 30 postoperative days, and three were operated under the emergency setting. The 30 -day mortality rate was $3 \%(1 / 33)$ for elective surgery and $12.5 \%(3 / 24)$ for emergency surgery. The overall 30 -day mortality rate was $7 \%$, with postoperative pneumonia being the cause of death in all (Table 2).

The overall 180 -day mortality rate was $31.6 \%$. The 6month survival rate was $75.8 \%$ (25/33) for elective surgery and $58.3 \%$ (14/24) for emergency surgery. The most common cause of death was pneumonia (42.9\%), followed by terminal malignancy (21.4\%). There were only three more deaths from 6 months to 1 year after surgery, and they were all attributed to terminal malignancy.

The 1 and 2-year survival rates for elective surgery were $69.7 \%$ (23/33) and 54.5\% (18/33), respectively. The 1 and 2-year survival rates for emergency surgery were $54.2 \%(13 / 24)$ and $37.5 \%$ (9/24), respectively (Fig. 1).

The factors associated with postoperative complications are shown in Table 3. Patients with ASA $4(p=$ $0.039)$, history of ischemic heart disease $(p=0.017)$, 
Table 1 Patient demographics, tumor characteristics and surgical procedures

\begin{tabular}{|c|c|c|}
\hline & $n$ & $\%$ \\
\hline \multicolumn{3}{|l|}{ Sex } \\
\hline Male & 20 & 35.1 \\
\hline Female & 37 & 64.9 \\
\hline \multicolumn{3}{|l|}{ ASA } \\
\hline 2 & 24 & 42.1 \\
\hline 3 & 30 & 52.6 \\
\hline 4 & 3 & 5.3 \\
\hline \multicolumn{3}{|l|}{ ECOG } \\
\hline 2 & 21 & 36.8 \\
\hline 3 & 28 & 49.1 \\
\hline 4 & 8 & 14.0 \\
\hline \multicolumn{3}{|l|}{ Tumor location } \\
\hline Colon & 38 & 66.7 \\
\hline Rectum & 19 & 33.3 \\
\hline \multicolumn{3}{|l|}{ Stage^^} \\
\hline 1 & 4 & 7.0 \\
\hline 2 & 23 & 40.4 \\
\hline 3 & 20 & 35.1 \\
\hline 4 & 6 & 10.5 \\
\hline Unknown & 4 & 7.0 \\
\hline \multicolumn{3}{|l|}{ Procedures } \\
\hline $\begin{array}{l}\text { Right / extended right hemicolectomy } \\
\text { / transverse colectomy }\end{array}$ & 25 & 43.9 \\
\hline Hartmann's procedure & 9 & 15.8 \\
\hline $\begin{array}{l}\text { Left hemicolectomy / sigmoidectomy / } \\
\text { anterior resections }\end{array}$ & 8 & 14.0 \\
\hline Low anterior resection & 7 & 12.3 \\
\hline Subtotal colectomy & 3 & 5.3 \\
\hline Diversion stoma & 3 & 5.3 \\
\hline Bypass & 2 & 3.5 \\
\hline
\end{tabular}

$\wedge$ According to the 8th American Joint Committee on Cancer (AJCC) staging classification

colon cancer $(p=0.031)$, and those who underwent emergency surgery $(p=0.044)$ were at significantly higher risk of developing complications. ASA $4(p=0.002)$, history of ischemic heart disease $(p=0.031)$, and emergency surgery $(p=0.059)$ were also associated with postoperative respiratory complications (data not shown).

ASA $4(p=0.011)$, CCI score $\geq 9(p=0.042)$, serum albumin level $(p=0.041)$, pneumonia $(p \leq 0.001)$, and overall complications $(p=0.012)$ had a significant association with 30-day mortality. All of these, together with preoperative leukocytosis $(p=0.021)$ were also associated with 180-day mortality.

Multivariate analysis revealed that emergency surgery $(p=0.025$, odds ratio 4.2$)$ and a history of ischemic heart
Table 2 Causes of death at various time intervals after operation

\begin{tabular}{ll}
\hline Days post-operation & $\%$ \\
\hline Within 30 days & 100 \\
Pneumonia & \\
Within 180 days & 42.9 \\
Pneumonia & 21.4 \\
Terminal malignancy & 14.3 \\
Unknown & 7.1 \\
Sepsis & 7.1 \\
Stroke & 7.1 \\
Dermatomyositis & \\
Beyond 180 days & 51.5 \\
Pneumonia & 21.2 \\
Terminal malignancy & 12.1 \\
Unknown & 6.1 \\
Stroke & 3.0 \\
Acute myocardial infarction & 3.0 \\
Perforated viscus & 3.0 \\
Cholangitis & \\
\hline
\end{tabular}

disease $(p=0.016$, odds ratio 17.6$)$ were predictors of postoperative complications. Pneumonia $(p=0.004$, odds ratio 33.1 ), preoperative leukocytosis $(p=0.005$, odds ratio 1.3 ), and CCI score of $\geq 9$ ( $p=0.059$, odds ratio 4.8$)$ were independent predictors of 180-day mortality (Table 4).

There were 10 patients operated on during the last 5 years of the study period. This group of patients outperformed their predecessors by achieving a better overall 2-year survival (Table 5).

\section{Discussion}

According to the Global Health and Ageing report from the World Health Organization, the number of people aged 65 or above was projected to increase from an estimated 524 million in 2010 to nearly 1.5 billion in 2050, with much of these in developing countries. The recent increase in life expectancy and improvement in health care was associated with a change in the leading cause of death from infectious to chronic diseases, including cancer.

There is ample evidence that major surgery could be safely performed in the elderly [10], typically in the age group of 70 or above. However, there are still concerns about performing surgery in very old patients. In previous studies, the mortality rate after surgery for colorectal malignancies ranged from 3.4 to $7 \%[11,12]$. Data on the operative outcomes after colorectal resections for nonagenarians were scarce. Indeed, age and comorbidities were shown to have a negative impact on the surgical outcomes. A Dutch study showed that advanced age and comorbidities were associated with early postoperative mortality after surgery for 


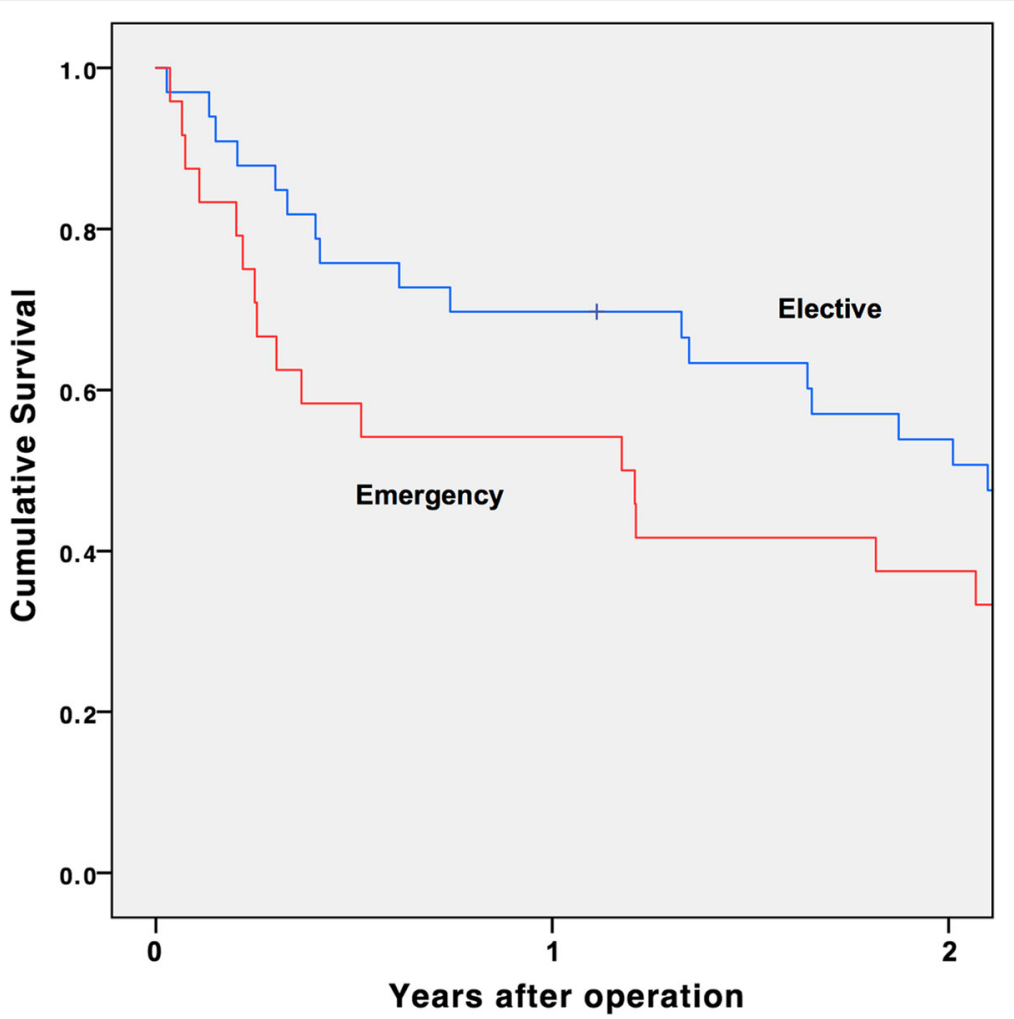

Fig. 1 Kaplan-Meier curves showing the cumulative survival after elective and emergency surgery

gastrointestinal malignancies [13]. Furthermore, Yeo et al. demonstrated that the incidence of adverse events and the likelihood of postoperative mortality increased when patients were older than 75 , and the risk increased further if the age was greater than 85 [14]. However, with an ageing population that continues to grow, surgeons will increasingly find themselves managing patients in this age group; thus, there is a requirement to evaluate whether or not they are good candidates for surgery.

One argument that supported elective surgical interventions in this group of patients was that they would present with surgical emergencies, such as intestinal obstruction, tumor perforation, and bleeding, and were subjected to an even higher surgical risk $[15,16]$. Owing to the lack of health awareness, social neglect, and poor accessibility to healthcare service, elderly patients are already more likely to present late with advanced disease. Worse still, they often present with an acute surgical condition that requires emergency surgery [7]. A United States population-wide study showed that the percentage of cases operated on an emergency basis rose from $5.9 \%$, for those $<65$ years of age, to $8.9 \%$ for those older than 85 years of age [14].

This study demonstrated that, in selected patients, acceptable outcomes could be achieved in nonagenarian patients. The postoperative mortality in this series was comparable to that previously reported in the literature
[17]. The 30-day mortality rate after elective resections in the nonagenarian patients was comparable to that of the younger elderly population. For example, statistics from a population-based study from the American College of Surgeons National Surgical Quality Improvement Program database showed that the 30 day mortality after colon and rectal surgery was 4.1 and $2.4 \%$, respectively for patients between 75 and 84 years of age [14]. It was also shown that more than half of the patients in this study cohort survived more than 2 years after elective surgery. Logically, the longer-term survival, e.g. 5 years, could not be compared to the younger elderly patients.

One important parameter of surgical outcome was the 6 month survival rate. As shown in this study, a substantial portion of the patients succumbed during the first 6 months, despite surviving the first 30 days. A previous study has shown that a major portion of elderly postoperative mortality occurred after the index hospitalization [14]. Furthermore, many were discharged to nursing homes or institutional care facilities after the index operation. This highlighted the need for improved support for these individuals in the early post-hospitalization period.

Operation risk evaluation and patient selection is of paramount importance in treating nonagenarian patients, and various methods have been proposed to quantify a patient's health status and to predict surgical outcomes [18]. Elderly individuals who are functionally 
Table 3 Factors associated with postoperative complications, 30-day mortality \& 180-day mortality

\begin{tabular}{|c|c|c|c|c|c|c|}
\hline \multirow[t]{2}{*}{ Factors } & \multicolumn{2}{|c|}{ Postoperative complications } & \multicolumn{2}{|c|}{ 30-day mortality } & \multicolumn{2}{|c|}{ 180-day mortality } \\
\hline & (\%) & $p$ & (\%) & $p$ & (\%) & $p$ \\
\hline Sex & & 0.568 & & 0.119 & & 0.683 \\
\hline Male & 40 & & 15 & & 35 & \\
\hline Female & 32.4 & & 2.7 & & 29.7 & \\
\hline ASA & & 0.039 & & 0.011 & & 0.028 \\
\hline$\|-\| \|$ & 31.5 & & 3.7 & & 27.8 & \\
\hline IV & 100 & & 66.7 & & 100 & \\
\hline ECOG & & 1.0 & & 0.464 & & 0.094 \\
\hline$<4$ & 34.7 & & 6.1 & & 26.5 & \\
\hline$\geq 4$ & 37.5 & & 12.5 & & 62.5 & \\
\hline $\mathrm{CCl}$ & & 0.53 & & 0.042 & & 0.025 \\
\hline$<9$ & 32.6 & & 2.3 & & 23.3 & \\
\hline$\geq 9$ & 42.9 & & 21.4 & & 57.1 & \\
\hline Chronic smoker & & 1.0 & & 1.0 & & 1.0 \\
\hline No & 34.5 & & 7.3 & & 32.7 & \\
\hline Yes & 50 & & 0 & & 0 & \\
\hline Hypertension & & 0.898 & & 0.623 & & 0.526 \\
\hline No & 36 & & 4 & & 36 & \\
\hline Yes & 34.3 & & 9.3 & & 28.1 & \\
\hline Diabetes mellitus & & 1.0 & & 0.464 & & 0.698 \\
\hline No & 34.7 & & 6.1 & & 30.6 & \\
\hline Yes & 37.5 & & 12.5 & & 37.5 & \\
\hline Ischemic heart disease & & 0.017 & & 0.051 & & 0.072 \\
\hline No & 29.4 & & 3.9 & & 27.5 & \\
\hline Yes & 83.3 & & 33.3 & & 66.7 & \\
\hline Cerebrovascular disease & & 1.0 & & 0.464 & & 1.0 \\
\hline No & 34.7 & & 6.1 & & 32.7 & \\
\hline Yes & 37.5 & & 12.5 & & 25 & \\
\hline Respiratory disease & & 0.687 & & 0.07 & & 1.0 \\
\hline No & 34 & & 4 & & 32 & \\
\hline Yes & 42.8 & & 28.6 & & 28.6 & \\
\hline Chronic renal failure & & 1.0 & & 1.0 & & 1.0 \\
\hline No & 35.8 & & 7.5 & & 32.1 & \\
\hline Yes & 25 & & 0 & & 25 & \\
\hline Cirrhosis & & 1.0 & & 1.0 & & 1.0 \\
\hline No & 35.7 & & 7.1 & & 32.1 & \\
\hline Yes & 0 & & 0 & & 0 & \\
\hline Current antiplatelet use & & 0.332 & & 0.315 & & 0.646 \\
\hline No & 32.7 & & 5.8 & & 30.8 & \\
\hline Yes & 60 & & 20 & & 40 & \\
\hline Surgical urgency & & 0.044 & & 0.3 & & 0.162 \\
\hline Elective & 24.2 & & 3 & & 24.2 & \\
\hline Emergency & 50 & & 12.5 & & 41.7 & \\
\hline Surgical approach & & 0.182 & & 0.569 & & 0.303 \\
\hline
\end{tabular}


Table 3 Factors associated with postoperative complications, 30-day mortality \& 180-day mortality (Continued)

\begin{tabular}{|c|c|c|c|c|c|c|}
\hline \multirow[t]{2}{*}{ Factors } & \multicolumn{2}{|c|}{ Postoperative complications } & \multicolumn{2}{|c|}{ 30-day mortality } & \multicolumn{2}{|c|}{ 180-day mortality } \\
\hline & (\%) & $p$ & (\%) & $p$ & (\%) & $p$ \\
\hline Laparoscopic & 16.7 & & 0 & & 16.7 & \\
\hline Open & 40 & & 8.9 & & 35.6 & \\
\hline Surgical intent & & 0.346 & & 1.0 & & 0.087 \\
\hline Curative & 38.6 & & 6.8 & & 25 & \\
\hline Palliative & 23.1 & & 7.7 & & 53.8 & \\
\hline Tumor location & & 0.031 & & 1.0 & & 0.227 \\
\hline Colon & 44.7 & & 7.9 & & 36.8 & \\
\hline Rectum & 15.8 & & 5.2 & & 21.1 & \\
\hline Disease staging & & 0.651 & & 1.0 & & 0.351 \\
\hline $1-3$ & 36.2 & & 6.4 & & 27.7 & \\
\hline 4 & 16.7 & & 0 & & 50 & \\
\hline \multicolumn{7}{|l|}{ Serum biochemistry^ } \\
\hline Hemoglobin & & 0.173 & & 0.852 & & 0.189 \\
\hline White cell count & & 0.566 & & 0.981 & & 0.021 \\
\hline Albumin & & 0.629 & & 0.041 & & 0.008 \\
\hline Creatinine & & 0.675 & & 0.473 & & 0.885 \\
\hline Overall complications & & & & 0.012 & & 0.005 \\
\hline No & & & 0 & & 18.9 & \\
\hline Yes & & & 20 & & 55 & \\
\hline Pulmonary complications & & & & $<0.001$ & & 0.001 \\
\hline No & & & 0 & & 22.4 & \\
\hline Yes & & & 50 & & 87.5 & \\
\hline Reoperation & & & & 1.0 & & 0.536 \\
\hline No & & & 7.3 & & 30.9 & \\
\hline Yes & & & 0 & & 50 & \\
\hline
\end{tabular}

$\wedge$ Analysis done by independent sample T test

dependent and malnourished are more prone to morbidities and mortality. The Comprehensive Geriatric Assessment takes into account the physical health, functional status, psychological health, and social support of this group of patients [19]. In addition, the Portsmouth-Physiological and Operative Severity Score for the enumeration of Mortality and morbidity score is another popular tool widely adopted in the United Kingdom, and studies have shown that it can reliably predict mortality after emergency laparotomy in elderly patients [20]. Recently there has been increasing interest in using sacropenia and frailty to predict surgical outcome after operations for gastrointestinal malignancies [21, 22].

In this study, three scoring systems that are wellvalidated and relatively easy to calculate were used: ASA, CCI, and ECOG performance status [23]. The ECOG is one of the most commonly used research tools to quantify the performance status of cancer patients [8]. The CCI was first proposed by Mary Charlson in 1987 and is the most extensively studied comorbidity index $[9,24]$.
It focuses on a list of selected co-morbidities, while the ECOG assesses the functional performance; they have both been shown to predict survival independent of the treatments [18]. This study confirmed that ASA 4 was associated with postoperative morbidity and mortality and that patients with a CCI score of $\geq 9$ were less likely to survive beyond 180 days after surgery. Performance status, as reflected by the ECOG score, was not a predictor of postoperative outcome in this study.

This study also showed that hypoalbuminemia was associated with a higher post-operative mortality rate. A previous study had established a similar relationship between hypoalbuminemia and a higher incidence of postoperative complications [25]. Furthermore, the serum albumin level reflects the nutritional status, and elderly patients with underlying malignant condition are at risk of malnutrition.

Rigberg et al. reviewed their experience with major general surgical operations in nonagenarians and reported an overall morbidity rate of $57 \%$, with pneumonia being the most common postoperative complication [26]. This was in line with 
Table 4 Multivariate analysis to identify the predictors of overall complications, 30-day mortality and 180-day mortality

\begin{tabular}{|c|c|c|c|}
\hline & $p$ & Odds Ratio & $95 \% \mathrm{Cl}$ \\
\hline \multicolumn{4}{|l|}{ Overall complications } \\
\hline ASA 4 & 0.105 & & \\
\hline Ischemic heart disease & 0.016 & 17.6 & $1.7-184.0$ \\
\hline Emergency surgery & 0.025 & 4.2 & $1.2-14.8$ \\
\hline Tumor location & 0.208 & & \\
\hline \multicolumn{4}{|l|}{ 30-day mortality } \\
\hline ASA 4 & 0.465 & & \\
\hline $\mathrm{CCl}(<9 / \geq 9)$ & 0.157 & & \\
\hline Ischemic heart disease & 0.465 & & \\
\hline Respiratory disease & 0.102 & & \\
\hline Overall complications & 1.000 & & \\
\hline Pulmonary complications & 0.997 & & \\
\hline Serum albumin level & 0.199 & & \\
\hline \multicolumn{4}{|l|}{ 180-day mortality } \\
\hline ASA 4 & 0.406 & & \\
\hline $\operatorname{ECOG}(<4 / \geq 4)$ & 0.113 & & \\
\hline $\mathrm{CCl}(<9 / \geq 9)$ & 0.059 & 4.8 & $0.9-24.1$ \\
\hline Ischemic heart disease & 0.235 & & \\
\hline Surgical intent & 0.201 & & \\
\hline Overall complications & 0.080 & & \\
\hline Pulmonary complications & 0.004 & 33.1 & $3.1-358.5$ \\
\hline Serum albumin level & 0.195 & & \\
\hline White cell count & 0.005 & 1.3 & $1.1-1.6$ \\
\hline
\end{tabular}

the current study, which identified pneumonia with respiratory failure as the most common postoperative complication and the leading cause of mortality, despite having a high proportion of non-smokers in the current study. A metaanalysis showed that laparoscopic colorectal resection has a lower incidence of postoperative pneumonia compared to the open approach, with an odds ratio of 0.53 [27].

An Australian study by Yap et al. on nonagenarians who underwent colorectal resections demonstrated, by incorporating a physician's input into the perioperative care, that the 30-day and 180-day mortality could be as low as 2.1 and $10.4 \%$, respectively; patients in the study had a much lower (2\%) incidence of pneumonia [16].

Table 5 A comparison of patients enrolled in the first 15 years and the last 5 years of the study period

\begin{tabular}{llll}
\hline & First 15 years & Last 5 years & $p$ value \\
\hline Complications & $38.3 \%$ & $40 \%$ & 0.271 \\
30-day mortality & $8.5 \%$ & $10 \%$ & 0.339 \\
180-day mortality & $34 \%$ & $20 \%$ & 0.386 \\
1-year survival & $59.6 \%$ & $70 \%$ & 0.224 \\
2-year survival & $40.4 \%$ & $60 \%$ & 0.023 \\
\hline
\end{tabular}

These encouraging results demonstrated the importance of multi-disciplinary care in the extreme elderly. In addition, patients undergoing laparoscopic surgery were shown to have better survival rates compared to those undergoing open surgery. However, this could be subjected to selection bias, as those undergoing open surgery may have more locally advanced disease and poorer cardiorespiratory reserve, which would prevent pneumoperitoneum. However, this echoed the finding of the above meta-analysis with lower incidence of respiratory complications and was in line with other studies that showed similar favorable short-term outcomes after laparoscopic colorectal surgery [10, 28]. Although such a finding was not confirmed in the current study, further research is warranted to evaluate the potential of laparoscopic surgery in improving surgical outcome in the extreme elderly.

This study was a retrospective analysis of patients from a single tertiary center with a relatively small number of patients. One major limitation was that the results were subjected to selection bias. The patients selected for surgery were regarded as having a reasonably good risk. A median follow-up period of 15.9 months was relatively short, but this was related to the limited lifespan of the patients who were senile to begin with. Moreover, only morbidity and mortality information were available, the quality of life and functional outcomes were not reported. Also, the study included a span of 20 years, in which some of the clinical practices had changed. For example, there was an increase in the use of laparoscopic approach since the year 2002, and the adoption of enhanced recovery after the surgery protocol in the year 2007.

\section{Conclusion}

Advanced age alone should not preclude surgery in patients with colorectal cancer. A comprehensive risk profiling taking into account the co-morbidities, ASA, and CCI score is crucial. Nutritional status should be optimized, and measures should be taken to prevent postoperative pneumonia. A favorable outcome could be achieved in a selected group of nonagenarian patients.

Abbreviations

ASA: American Society of Anesthesiologists; CCl: Charlson comorbidity index; ECOG: Eastern Cooperative Oncology Group

Acknowledgements

Not applicable.

\section{Authors' contributions}

TYC analyzed and interpreted the data and was a major contributor in writing the manuscript. CCF analyzed and interpreted the data and revised the manuscript. WLL interpreted the data and provided supervision in this study. OL provided administrative support and revised the manuscript. All authors read and approved the final manuscript. 


\section{Availability of data and materials}

The dataset analyzed during the current study is available from the corresponding author on reasonable request.

\section{Ethics approval and consent to participate}

This study was performed in accordance with the Declaration of Helsinki and was approved by the Institutional Review Board of the University of Hong Kong / Hospital Authority (UW 18-229).

\section{Consent for publication}

Not applicable as there is no identifiable material in this manuscript.

\section{Competing interests}

The authors declare no that they have no competing interests.

\section{Author details}

'Department of Surgery, Queen Mary Hospital, Hong Kong, China. ${ }^{2}$ Department of Surgery, The University of Hong Kong, 102 Pokfulam Road, Hong Kong, China.

Received: 11 July 2019 Accepted: 10 October 2019

Published online: 28 October 2019

\section{References}

1. Department of Economic and Social Affairs. The world population prospects. 2015 revision. United Nations; 2015.

2. Abridged Life Tables for Japan. Ministry of Health, Labour and Welfare, Japan. 2016. https://www.mhlw.go.jp/english/database/db-hw/lifetb16/dl/ lifetb16-03.pdf. Accessed 20 March 2017.

3. Census and Statistics Department. Hong Kong population projections 20172066. 2017 edn. The Government of the Hong Kong Special Administrative Region; 2017.

4. Statistica: The countries with the highest life expectancy. In.: World Health Organisation; 2015.

5. Tomimaru Y, Ide Y, Murata K. Outcome of laparoscopic surgery for colon cancer in elderly patients. Asian journal of endoscopic surgery. 2011:4(1):1-6.

6. Global, regional, and national age-sex specific all-cause and cause-specific mortality for 240 causes of death, 1990-2013: A systematic analysis for the global burden of disease study 2013. Lancet (London, England) 2015, 385(9963):117-171.

7. Surgery for colorectal cancer in elderly patients: a systematic review. Colorectal Cancer Collaborative Group. Lancet (London, England) 2000, 356(9234):968-974.

8. Oken MM, Creech RH, Tormey DC, Horton J, Davis TE, McFadden ET, Carbone PP. Toxicity and response criteria of the eastern cooperative oncology group. Am J Clin Oncol. 1982;5(6):649-55.

9. Charlson ME, Pompei P, Ales KL, MacKenzie CR. A new method of classifying prognostic comorbidity in longitudinal studies: development and validation. J Chronic Dis. 1987:40(5):373-83.

10. Law WL, Chu KW, Tung PH. Laparoscopic colorectal resection: a safe option for elderly patients. J Am Coll Surg. 2002;195(6):768-73.

11. Alves A, Panis Y, Mathieu P, Mantion G, Kwiatkowski F, Slim K: Postoperative mortality and morbidity in French patients undergoing colorectal surgery: results of a prospective multicenter study. Archives of surgery (Chicago, III : 1960) 2005, 140(3):278-283, discussion 284.

12. Fielding LP, Phillips RK, Hittinger R: Factors influencing mortality after curative resection for large bowel cancer in elderly patients. Lancet (London, England) 1989, 1(8638):595-597.

13. van Gestel YR, Lemmens VE, de Hingh IH, Steevens J, Rutten HJ, Nieuwenhuijzen GA, van Dam RM, Siersema PD. Influence of comorbidity and age on 1-, 2-, and 3-month postoperative mortality rates in gastrointestinal cancer patients. Ann Surg Oncol. 2013;20(2):371-80.

14. Yeo HL, O'Mahoney PR, Lachs M, Michelassi F, Mao J, Finlayson E, Abelson JS, Sedrakyan A. Surgical oncology outcomes in the aging US population. J Surg Res. 2016;205(1):11-8.

15. Morse BC, Cobb WS, Valentine JD, Cass AL, Roettger RH. Emergent and elective colon surgery in the extreme elderly: do the results warrant the operation? Am Surg. 2008;74(7):614-8 discussion 618-619.

16. Yap R, Oliva K, Wilkins S, McMurrick PJ. Colorectal Cancer surgery in the very elderly: nonagenarians. Dis Colon Rectum. 2016;59(6):501-7.
17. Tokuoka M, Ide Y, Takeda M, Hirose H, Hashimoto Y, Matsuyama J, Yokoyama S, Fukushima Y, Sasaki Y. Single-port versus multi-port laparoscopic surgery for colon cancer in elderly patients. Oncol Lett. 2016; 12(2):1465-70.

18. Monson K, Litvak DA, Bold RJ: Surgery in the aged population: surgical oncology. Archives of surgery (Chicago, III : 1960) 2003, 138(10):1061-1067.

19. Kim Kl, Park KH, Koo KH, Han HS, Kim CH. Comprehensive geriatric assessment can predict postoperative morbidity and mortality in elderly patients undergoing elective surgery. Arch Gerontol Geriatr. 2013;56(3):507-12.

20. Sharrock AE, McLachlan J, Chambers R, Bailey IS, Kirkby-Bott J. Emergency abdominal surgery in the elderly: can we predict mortality? World J Surg. 2017;41(2):402-9.

21. Nakanishi R, Oki E, Sasaki S, Hirose K, Jogo T, Edahiro K, Korehisa S, Taniguchi D, Kudo K, Kurashige J, et al. Sarcopenia is an independent predictor of complications after colorectal cancer surgery. Surg Today. 2018;48(2):151-7.

22. Okabe H, Ohsaki T, Ogawa K, Ozaki N, Hayashi H, Akahoshi S, Ikuta Y, Ogata $\mathrm{K}$, Baba $\mathrm{H}$, Takamori H. Frailty predicts severe postoperative complications after elective colorectal surgery. Am J Surg. 2018.

23. Yancik R, Wesley MN, Ries LA, Havlik RJ, Long S, Edwards BK, Yates JW. Comorbidity and age as predictors of risk for early mortality of male and female colon carcinoma patients: a population-based study. Cancer. 1998; 82(11):2123-34

24. de Groot V, Beckerman H, Lankhorst GJ, Bouter LM. How to measure comorbidity. A critical review of available methods. J Clin Epidemiol. 2003; 56(3):221-9.

25. Park SY, Chung JS, Kim SH, Kim YW, Ryu H, Kim DH. The safety and prognostic factors for mortality in extremely elderly patients undergoing an emergency operation. Surg Today. 2016;46(2):241-7.

26. Rigberg D, Cole M, Hiyama D, McFadden D. Surgery in the nineties. Am Surg. 2000;66(9):813-6.

27. Li Y, Wang S, Gao S, Yang C, Yang W, Guo S. Laparoscopic colorectal resection versus open colorectal resection in octogenarians: a systematic review and meta-analysis of safety and efficacy. Techniques in coloproctology. 2016;20(3):153-62.

28. Audisio RA, Cazzaniga M, Robertson C, Veronesi P, Andreoni B, Aapro MS. Elective surgery for colorectal cancer in the aged: a clinical-economical evaluation. Br J Cancer. 1997;76(3):382-4.

\section{Publisher's Note}

Springer Nature remains neutral with regard to jurisdictional claims in published maps and institutional affiliations.

Ready to submit your research? Choose BMC and benefit from:

- fast, convenient online submission

- thorough peer review by experienced researchers in your field

- rapid publication on acceptance

- support for research data, including large and complex data types

- gold Open Access which fosters wider collaboration and increased citations

- maximum visibility for your research: over $100 \mathrm{M}$ website views per year

At BMC, research is always in progress.

Learn more biomedcentral.com/submissions 